\title{
Sobre a relação entre Educação $e$ Psicanálise no contexto das novas formas de subjetivação
}
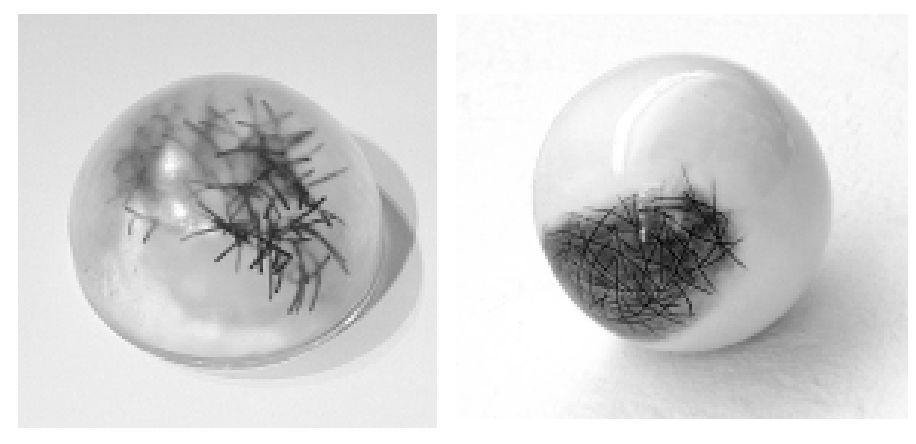

Maria Regina Maciel ${ }^{1}$

MACIEL, M. R. On the relation between education and psychoanalysis in the context of new forms of subjectivity. Interface - Comunic., Saúde, Educ., v.9, n.17, p.333-42, mar/ago 2005.

This article explores the relationship between education and psychoanalysis in the context of new forms of subjectivity. It discusses Freud's references to education, as well as some of the most recent works on the theme. Taking into account the changes that both fields have undergone regarding their theories and their practices, it proposes an intersection between them, to take place within the school environment, contributing to the emergence of more creative subjects.

KEY-WORDS: education; psychoanalysis; singularities; creativity.

Este artigo tece relações entre educação e psicanálise no contexto das novas formas de subjetivação. Discute as referências de Freud à educação, bem como algumas das mais recentes publicações sobre o tema. Levando em consideração as transformações por que têm passado ambos os campos em suas teorias e em suas práticas, propõe uma interseção entre eles, que se daria no espaço escolar, contribuindo para a existência de sujeitos mais criativos.

PALAVRAS-CHAVE: educação; psicanálise; singularidades; criatividade.

\footnotetext{
${ }^{1}$ Psicanalista, professora adjunta, Universidade do Estado do Rio de Janeiro (UERJ), Rio de Janeiro, RJ. <mrmaciel@ig.com.br>
} 


\section{Introdução}

A proposta deste artigo é fazer um balanço preliminar da relação entre psicanálise e educação no contexto das novas formas de subjetivação. Nesse novo contexto, é fundamental refletir sobre que subjetividade e que tipo de cidadania queremos ter como alvo e finalidade nas práticas educacionais contemporâneas. Uma questão central na atualidade é pensar sobre o que significa educar e psicanalisar hoje, diante da crise de fundamentos nos saberes que norteavam nossas práticas, até então, de forma inconteste.

Com tal proposta em mente, iremos nos reportar, primeiramente, às referências de Freud quanto à educação, posto que são os textos fundadores desta reflexão. Em seguida, passaremos a nos referir às articulações feitas por alguns pesquisadores, nos últimos anos, sobre as relações entre esses dois saberes. No que tange especificamente a esse segundo eixo de análise, é importante assinalar o crescente interesse pelo estudo das relações entre psicanálise e educação, tanto entre educadores, quanto entre psicanalistas. O entrecruzamento desses dois campos de saber tem uma história marcada por variadas tendências. Num preliminar levantamento bibliográfico sobre o tema entre os psicanalistas, é possível afirmar que, nas mais recentes publicações (últimos cinco anos), predomina uma proposta de junção desses dois campos, diferentemente do que ocorria há dez ou vinte anos atrás, quando predominava um tipo de leitura da questão em que se ressaltavam as impossibilidades de encontro entre eles. O que aconteceu para que essa mudança de posição tenha ocorrido?

Sabemos que estamos vivendo, segundo diversos autores das ciências humanas e sociais, um momento em que se verifica uma série de problemas nos atuais processos de subjetivação e nas patologias a eles associadas. Dentre eles, podemos destacar dois: a apatia e a denominada "cultura do narcisismo", na qual podem-se observar atos de violência sem qualquer objetivo de transformação ou projeto histórico. O terceiro e último sub-item do presente texto diz respeito, portanto, à maneira como a psicanálise e a educação podem contribuir, ao se encontrarem no espaço escolar, para a existência de sujeitos mais criativos. São considerados como temas balizadores desta articulação o processo de subjetivação, a criatividade e a singularidade.

\section{Referências de Freud à educação}

Podemos afirmar que, basicamente, as contribuições de Freud à educação dizem respeito primeiramente à transmissão de conhecimento através dos Inconscientes. Devemos esclarecer que o Inconsciente é o conceito fundamental da psicanálise, sendo considerado por ele a terceira ferida narcísica da humanidade (Freud, 1917 a e b) ${ }^{2}$. Com esse conceito, podemos nos conceber também como sujeitos do desconhecimento, no qual algo sempre escapa à pretensão de controle consciente, como, por exemplo, de tudo o que aprendemos.

Outra referência de Freud à educação diz respeito à importância da relação professor-aluno, o que nos leva a pensar na questão da transferência sob o aspecto de um fenômeno que não se passa apenas entre paciente $e$ terapeuta, mas que perpassa todas as relações humanas. Embora o que se

\footnotetext{
${ }^{2}$ Freud, em dois de seus textos (1917 a e b), se refere a "três severos golpes" sofridos pelo homem no seu "amor próprio", no seu "narcisismo universal". O primeiro ocorreu com Copérnico e seu "golpe cosmológico", quando a terra deixou de ser vista como o centro do universo. $\mathrm{O}$ segundo, com Darwine seu "golpe biológico", quando o homem deixou de ter uma ascendência divina sobre os animais. E o terceiro, finalmente, com o Inconsciente $e$ seu "golpe psicológico" quando deixamos de ser "senhor de nossa própria casa”.
} 
${ }^{3} \mathrm{~A}$ noção de sujeito do desejo em psicanálise se refere ao fato deste se relacionar não só com objetos de necessidade, mas também com objetos de desejo que passam pelos significados construídos nas interações que os sujeitos estabelecem entre si. passa na escola seja diferente, na psicanálise a transferência constitui seu próprio instrumento de trabalho.

Finalmente, uma terceira contribuição encontrada nos textos freudianos aponta para o papel da educação como auxiliar da sublimação sexual (já que seus argumentos afirmam que a curiosidade intelectual é derivada da curiosidade sexual). Quanto a essa última referência, devemos ter em mente que esse desvio pulsional necessário não deve ser excessivo e chegar a inibir o sujeito do desejo ${ }^{3}$.

Alguns de seus textos que mencionam a educação são:

- "Recomendações aos médicos que exercem a psicanálise" (Freud, 1912), no qual, ao ligar a atividade educativa à capacidade sublimatória $e$ ao se referir às indicações feitas pelos professores de livros a serem lidos, alerta para o risco de os educadores quererem modificar os alunos à sua imagem, tomando para si a função de modelo.

- "Algumas reflexões sobre a psicologia escolar" (Freud, 1914), no qual afirma que a aquisição de conhecimento depende da relação do aluno com seus professores e seus colegas, numa referência à relação transferencial que faz com eles, enquanto representantes de seus pais e irmãos. Em suas palavras: "... é difícil dizer se o que exerceu mais influência sobre nós e teve importância maior foi nossa preocupação pelas ciências que nos eram ensinadas, ou pela personalidade de nossos mestres" (p. 286). É importante mencionar que o conceito de transferência designa o processo utilizado pelos desejos inconscientes para, não só na relação analítica, repetir nossas experiências infantis vividas, agora, como atualidade.

- "Prefácio à juventude desorientada de Aichhorn" (Freud, 1925). Nesse texto, ao mencionar a importância do professor para o aluno - posto que aquele pode orientá-lo, servindo como modelo -, Freud aponta para o valor profilático de uma psicanálise para o próprio educador. Este não tem, portanto, que se contentar somente com uma instrução teórica da teoria psicanalítica.

- "Explicações, aplicações e orientações" em Novas Conferências Introdutórias à psicanálise (Freud, 1933), no qual se refere à tentativa da "educação psicanalítica" procurar um "ponto ótimo" que possibilite "proibição de pulsão" sem "doença neurótica". Freud afirma que cada criança tem seu ponto. Isso nos leva a questionar o valor de uma educação de massa e pré-programada, pois nos parece colocar aí a questão da singularidade. A partir dessa menção, podemos dizer que o professor não tem controle total dos efeitos de suas palavras sobre os alunos. Não saberá o que o aluno fará com aquelas idéias e com o que as associará.

- "Análise terminável e interminável” (Freud, 1937), no qual afirma que o psicanalisar, o educar e o governar são profissões impossíveis, posto que sempre chegam a resultados insatisfatórios.

Entretanto, a partir das indicações deixadas por Freud, que desenvolvimento essas relações sofreram nos últimos anos?

\section{Articulações contemporâneas entre Psicanálise e Educação} O livro de Millot, publicado pela primeira vez na França, em 1979, marcou aqueles que estudam o campo da interseção educação/psicanálise (Millot, 
MACIEL, M. R.

1987). Ele foi, pode-se dizer, uma referência obrigatória para os interessados nessa conexão. No seu livro, a autora afirmava a impossibilidade de aplicar psicanálise à educação. No máximo, a psicanálise poderia transmitir ao educador uma ética, um modo de ver e de entender a prática educativa.

Seguindo os ensinamentos de Lacan, a posição de Millot radicalizava as separações existentes entre esses dois campos. Ela se contrapunha claramente à tradição psicanalítica que entendia a psicanálise como educação das pulsões, tendo um objetivo profilático com relação às neuroses. Anna Freud encaixavase aqui como uma representante dessa outra tendência, na qual tanto educadores quanto psicanalistas deviam colar-se ao lugar do saber. Ou seja, a análise da criança era associada a medidas educativas, tendendo a transformarse em pedagogia (Freud, 1971). Esse tipo de posição era, portanto, criticada por Millot.

No Brasil, Kupfer, dez anos depois da publicação do livro de Millot, seguia a mesma linha de raciocínio (Kupfer, 1989). No entanto, em seu mais recente livro, publicado em 2001, a mesma autora confessa que mudou de idéia no que tange à afirmação anterior de que psicanálise e educação não se casavam. Hoje, ela admite que é possível conceber uma educação orientada pela psicanálise. Propõe, assim, a "educação terapêutica" como "conjunto de práticas interdisciplinares de tratamento, com especial ênfase nas práticas educacionais, que visa à retomada do desenvolvimento global da criança”. A educação terapêutica, segundo a autora,

não é mais psicanálise em seu sentido clássico, pois não busca tocar o real pelo simbólico e sim instituir o simbólico em torno do real; não é apenas educação em seu sentido clássico, pois não visa moldar a criança ao ideal do eu do educador, já que a criança psicótica quase nunca está atenta aos ideais e, portanto, não coloca o educador no lugar de modelo identificatório como fazem as outras crianças. Também não é educação 'stricto sensu', porque seu tempo já passou e qualquer esforço de retomá-la produzirá algo novo, e será sempre uma reeducação. (Kupfer, 2001, p.83, 115)

A autora estende, inclusive, sua proposta de "educação terapêutica" para ser aplicada não só à educação especial (de crianças psicóticas e autistas, por exemplo), mas para a educação de crianças de maneira mais ampla (Kupfer, 2001). Temos aí um exemplo de como esses dois campos foram se entrelaçando cada vez mais com o passar dos anos.

Em um livro publicado também no Brasil (Bacha, 2002), vemos uma interessante ligação entre educação e psicanálise, vindo de uma outra tradição psicanalítica que não a lacaniana. Bacha (2002, p.20) propõe-se a

explorar a dimensão imaginária dos processos cognitivos, aprimorando a sua performance, ampliando o seu pensamento, alargando a sua capacidade de conhecer e de se conhecer. $\mathrm{E}$, finalmente, 'formar' o leitor iniciando-se nessa realidade surreal tramada pelo artista com os fios da fantasia e da razão, e sonegada já na infância por uma formação indolente. 
${ }^{4}$ Ver Castoriadis, 1982 e 1997; e Valle, 2002.
Ela tenciona olhar para a educação pela perspectiva exclusiva da criança, que é diferente, segundo ela, da noção de psicologia do desenvolvimento e da aprendizagem. Ou seja, a autora não encerra a contribuição da psicanálise para a educação na noção de desenvolvimento humano (Bacha, 2002).

A perspectiva da criança, a que a autora se refere, diz respeito aos fantasmas inconscientes que a situação formativa acorda no professor. Isso é o que, segundo Bacha, deve ser trabalhado ao se pensar psicanálise e educação. A autora se pergunta: por que não fazer o professor se ver no lugar da criança? Para ensinar bem, é preciso "inquietar a razão e desfazer os hábitos do conhecimento objetivo". É preciso, portanto, reconhecer o inconsciente no território da razão, o que significa admitir a "surrealidade da educação" que aponta para o "fantasma da sedução" (Bacha, 2002, p.32 e 63).

A autora afirma que "educar é nutrir, e nutrir com Eros". Recorrendo a um trabalho de Renato Mezan - que analisou os vários aspectos da sedução e os agrupou em duas faces, a ética (que remete ao domínio de um indivíduo sobre o outro) e a estética (que pode vir a despertar ou a refinar uma sensibilidade)-, ela nos faz pensar no lugar do professor como o do sedutor, mas sedutor no sentido estético, um "Don Juan do bem", por assim dizer (Bacha, 2002, p.97). Esse livro se insere aqui com o intuito, portanto, de mostrar como nas mais recentes publicações acerca da relação psicanálise/educação esses laços têm sido refeitos.

No parágrafo anterior, referimo-nos à questão estética. Ao nos depararmos com tal questão na relação professor/aluno, na qual a construção dos conceitos pode adquirir uma dimensão de imaginação $e$ pode-se aprender criativamente, um autor que se impõe como fundamental é Castoriadis (1997; 1982). Ele nos permite unir psicanálise e educação, agora sob a ótica da criatividade. Seriam elas espaços possíveis de criação ${ }^{4}$

Castoriadis afirma a natureza indeterminada e indeterminável do fazer educativo. A partir da menção de Freud, em que o educar, junto ao psicanalisar e ao governar, são tidas como atividades impossíveis (Freud, 1937), Castoriadis as concebe como atividades prático-poéticas. Assim como a política e a psicanálise, a educação teria como finalidade a construção da autonomia humana, em outras palavras, a sua auto-criação.

Algo, no entanto, sempre escapa à pretensão desses três campos do saber. Isso ocorre exatamente porque há uma dimensão no humano que diz respeito a sua possibilidade de construir a si mesmo. E, contudo, esses três campos de saber sugerem uma intervenção externa, ali onde o que existe é a auto-criação. Caindo nesse engodo e esquecendo-se da liberdade humana, a educação, ao lado dos outros dois saberes, muitas vezes fica reduzida a um espaço de mera aplicação de teorias a priori. Teorias essas que são construídas pelos "especialistas" e passam ao largo das possíveis contribuições que poderiam dar, por exemplo, os próprios professores $e$ alunos que vivem o dia a dia de suas instituições.

Ainda recorrendo a Castoriadis, vale lembrar que o projeto de autonomia não deve ficar só no âmbito individual, mas é também um projeto necessariamente social. Por isso a necessidade de se criticar uma sociedade heteronômica em que o sujeito não pode exercer sua autonomia, posto que 
funciona à sua revelia. Esse tipo de sociedade é considerada não-democrática $e$ aliena o sujeito, encobrindo seu poder de auto-criação.

Assim, vemos a importância de não esquecer o âmbito da política ao abordarmos os laços possíveis entre psicanálise e educação. Neste sentido, o trabalho de Patto (1990), entre outros, é importante para que não se deixe de articular o discurso social ao se tentar entender, como psicanalistas $e$ educadores, um problema de aprendizagem, por exemplo. Esta autora nos mostra, sob esse aspecto, que o fracasso acadêmico se produz no interior das relações cotidianas do espaço escolar, as quais muitas vezes negam $e$ desqualificam a diferença social ou o desencontro de vivências e linguagens entre as crianças concretas de uma determinada escola $e$ o ideal esperado $e$ mais de acordo com o grupo social dominante.

\section{A Educação no contexto das novas formas de subjetivação}

É possível observar uma transformação geral no registro da construção das subjetividades contemporâneas. Entre essas mudanças, enfatizamos duas: um certo estilo de ser depressivo - uma certa apatia reinante nos processos de subjetivação contemporâneos - e a violência narcísica de atos distantes de qualquer ideal coletivo. Diversos são os autores que se referiram a esses aspectos. É o caso, por exemplo, de Sennett (2000; 1998), Birman (1999), Bauman (1998), Ehrenberg (1998), Costa (1984), Lipovetsky (1993) e Lasch $(1987 ; 1983)$.

Encontramo-nos em uma sociedade extremamente individualista que, longe de se contrapor às tendências da apatia e da violência narcísica acima citadas, pode vir a impedir tanto o exercício da criatividade, quanto o reconhecimento intersubjetivo das demandas de seus sujeitos. Seu extremo individualismo em nada contribui para aquilo que Winnicott $(1983$; 1975) chamou de "continuidade do sentimento de existência", que, sustentado pelo reconhecimento mútuo, permite que nossa "criatividade primária" se transforme efetivamente em "experiência criativa".

Pretendemos, no entanto, enfatizar, neste item do trabalho, a possibilidade de a educação e a psicanálise serem, ao contrário dessa tendência, espaços de criação democráticos e que estimulem os processos alteritários em detrimento dos narcísicos ${ }^{5}$. Nesse caso, propomos pensar, aqui, mais especificamente, em novas práticas educacionais alternativas que se encaminham por essa direção.

Tomemos o que se pode observar principalmente a partir dos anos 1980 - com as reivindicações das feministas, do multiculturalismo ou da terceira idade, para citar alguns exemplos -, quando vimos emergir novos sujeitos dos processos educativos. Esses novos sujeitos vivenciam a fragmentação das paisagens culturais de classe, gênero, etnia, nacionalidade etc., sob o aspecto daquilo que nos forneciam, até então, sólidas localizações como indivíduos sociais. Foram essas localizações, aliás, que, como nos mostra Hall, contribuíram para criar padrões de alfabetização universais (mediante um sistema educacional nacional), uma única língua, uma cultura homogênea (Hall, 2003).

Hoje, contudo, diante das híbridas nações culturais modernas e do fenômeno da globalização que, por seu turno, fez emergir uma tensão entre
${ }^{5}$ Em seus textos, como, por exemplo, "Além do princípio do prazer" (1920) e "O mal-estar na civilização" (1930), Freud afirma que a pulsão de vida/Eros (aquela que constitui ligações) e a pulsão de morte (aquela que é desagregadora) governam o processo vital. Este, por seu turno, é feito de processos narcísicos (nos quais nos voltamos para nós mesmos) e processos alteritários (nos quais somos postos para fora de nossa redoma narcísica autosuficiente, rumo aos objetos do mundo). 
o "global" e o "local", a educação necessita repensar-se e pôr na pauta de suas discussões a questão do local, da diferença, da singularidade, da alteridade, $e$ não apenas o tema do universal.

Levando-se em conta este tipo de discussão, um autor que também deve ser mencionado é Cambi. Ele afirma que essas novas emergências, de certa forma, obrigaram a educação - e nós acrescentaríamos, a psicanálise - a ser capaz de re-descrever seu papel e território de atuação. A educação pode, assim, mostrarse um campo teórico e prático aberto, sem estereótipos, que trabalha as diferenças, por exemplo, de gênero, de culturas "outras" (em relação à ocidental, greco-cristã-burguesa) etc. (Cambi, 1999).

$\mathrm{O}$ autor mencionado acima, ao se referir às questões educacionais contemporâneas, especificamente às da terceira idade, afirma: "isto implica a predisposição de 'percursos educativos': de aprendizagem (tipo universidade livre), de recreação (de jogo, de espetáculo, de viagem), de intercâmbio social (em associação de bairro ou outros)". Ele aponta aí, portanto, uma via concreta possível para a educação se colocar como um espaço mais criativo, buscando tornar-se um "saber aberto sobre as práxis formativas e capaz de iluminá-las criticamente, sem ir à procura de objetivos eternos e de certezas não variantes" (Cambi, 1999, p.405).

Filiamo-nos aqui a uma tradição libertária da Escola, na qual esta não só reproduz a sociedade, mas pode transformá-la. Acreditamos que o espaço escolar pode não só repetir a língua oficial, mas também fazer vir à tona os discursos esquecidos, massacrados. Nesse sentido, educação e psicanálise se aproximam enquanto campos teóricos e práticos em que se pretende dar espaço aos discursos latentes em detrimento aos manifestos.

Ainda neste intuito de aproximar psicanálise e educação, fazemos referências ao texto de Felman (2000). Seu artigo muito nos auxilia em nosso objetivo de articular psicanálise e educação por meio de temas como os das novas formas de subjetivação, da criatividade e da singularidade.

Felman parte da noção de trauma, tão pertinente ao nosso século de catástrofes históricas. Ela pergunta se o trauma poderá instruir a experiência pedagógica. Para uma resposta afirmativa, passa pelas lições literárias e psicanalíticas sobre o testemunho.

A autora faz-nos pensar sobre o valor do testemunho. Nele, texto e vida se fundem num processo singular e coletivo ao mesmo tempo. O testemunho, segundo ela, é uma prática discursiva, um ato de fala que pode criar o novo e gerar a verdade. Felman, portanto, discute este conceito como aquilo que nos faz deparar com a estranheza, que é imprevisível e só pode ser captado no movimento de sua própria produção. Afirma, então, que "testemunhar é, precisamente, engajar-se no processo de reencontrar seu nome próprio, sua assinatura" (Felman, 2000, p.64).

Em "Educação e crise, ou as vicissitudes do ensino" é oferecido um exemplo vivo da transformação nas subjetividades dos alunos mediante o relato da experiência da autora em um seminário de pós-graduação. É relatada a crise que se instalou em seus estudantes quando Felman proporcionou a eles contato com testemunhos de escritores e sobreviventes do holocausto. Ela afirma que, a partir daí, os próprios trabalhos escritos de final de curso "terminaram por ser uma declaração sobre o trauma pelo qual tinham passado 
e sobre a importância de terem assumido a posição de testemunha”. A autora termina por concluir que o ensinar ocorre apenas por meio de uma crise. Ensinar é, portanto, mais do que transmitir alguns fatos; é fazer algo acontecer. Segundo suas palavras: "o ensinar é uma atividade performática $e$ não cognitiva, como aliás a psicanálise, à medida que ambos lutam por produzir, e possibilitar, uma mudança" (Felman, 2000, p.66-7).

\section{Conclusão}

O encontro entre Educação e Psicanálise pode ser bastante frutífero. Ele tem uma história, que começa nos primeiros escritos de Freud sobre o tema e se estende até textos de psicanalistas e educadores mais contemporâneos.

No que se refere a este artigo, os temas das novas formas de subjetivação, criatividade e singularidade foram considerados os marcos desse embate. Estes temas podem ser articulados no valor do testemunho. Um ensino que dê espaço a nosso potencial narrativo, sem esquecer que somos dependentes uns dos outros na construção dessas narrativas, contribui para a existência de sujeitos mais presentes e atuantes na experiência do mundo e de si próprios.

Acreditamos que esses dois campos podem funcionar como campos teóricos/ práticos de auto-criação do sujeito. Eles podem ser tidos como práticas poéticas que visam à autonomia humana. Isso, se, por exemplo, a Escola puder ser um espaço de encontro intersubjetivo, no qual transformações podem ser operadas em seu cotidiano. Em outras palavras, se a Escola puder se fazer de lugar de passagem até que o aluno comece, ele próprio, a se interrogar.

Afirmamos o que foi dito acima, entretanto, sem desconhecer que a Escola, enquanto lugar de aplicação desses saberes, é também um lugar de reprodução do instituído, na qual questões como as desigualdades entre as classes sociais tendem a se repetir. Afinal, a Escola por si só não pode transformar a sociedade da qual é apenas um elemento. Ela depende também de políticas públicas efetivas e concretas do Estado.

Finalmente, é possível concluir que, além de ser lugar de "informação" da tradição - e, nesse sentido, comprometida com as diversas formas de dominação -, a Escola pode ser também lugar de "transmissão" - e, de certa maneira, espaço criativo de sujeitos singulares.
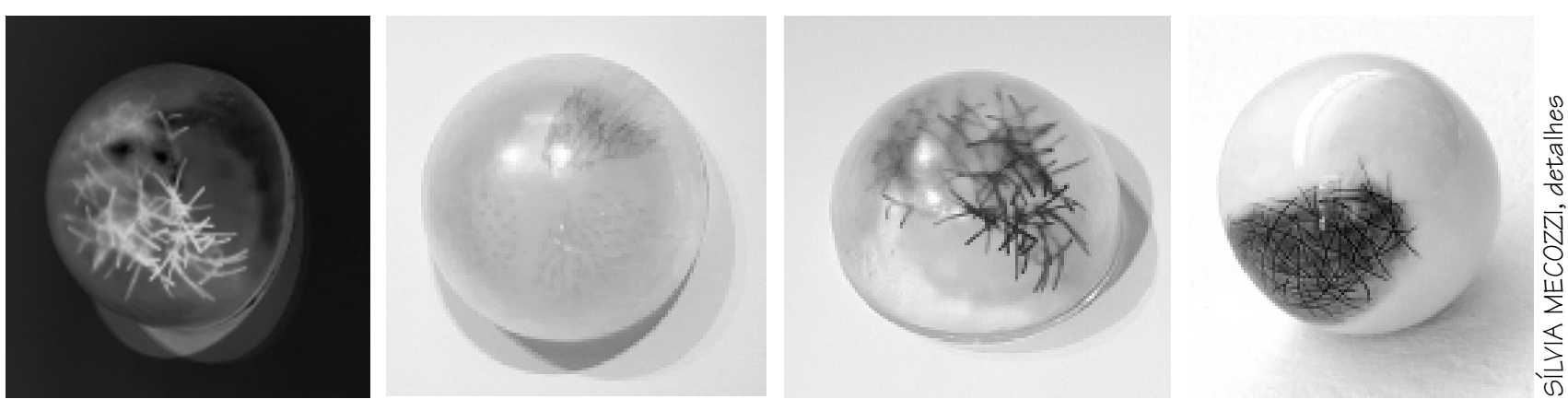

Interface - Comunic, Saúde, Educ, v.9, n.17, p.333-42, mar/ago 2005 

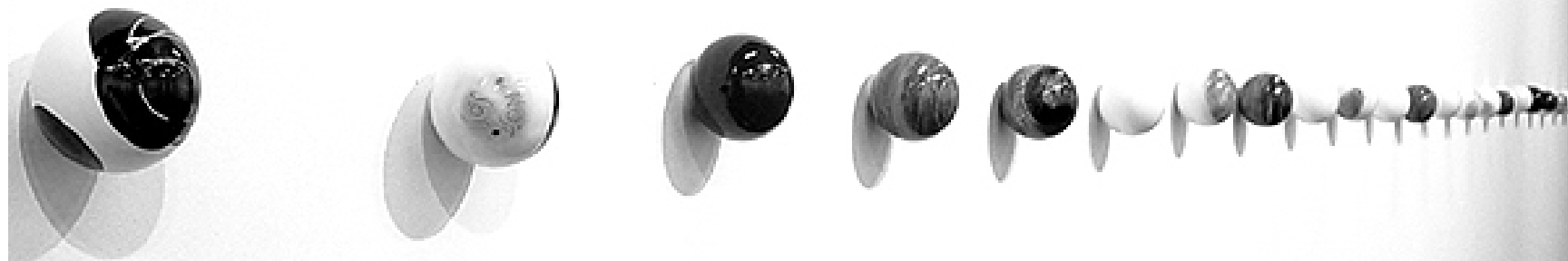

\section{Referências}

BACHA, M. N. A arte de formar: o feminino, o infantil e o epistemológico. Petrópolis: Vozes, 2002.

BAUMAN, Z. O mal-estar da pós-modernidade. Rio de Janeiro: Zahar, 1998.

BIRMAN, J. Mal-estar na atualidade: a psicanálise e as novas formas de subjetivação. Rio de Janeiro: Civilização Brasileira, 1999.

CAMBI, F. História da pedagogia. São Paulo: Ed. UNESP, 1999.

CASTORIADIS, C. A instituição imaginária da sociedade. Rio de Janeiro: Paz e Terra, 1982.

CASTORIADIS, C. As encruzilhadas do labirinto. Rio de Janeiro: Paz e Terra, 1997. v.1.

COSTA, J. F. Violência e psicanálise. Rio de Janeiro: Graal, 1984.

EHRENBERG, A. La fatigue d'être-soi: depresión et societé. Paris: Odile Jacob, 1998.

FELMAN, S. Educação e crise, ou as vicissitudes do ensino. In: NESTROVSKI, A.; SELEGMANN-SILVA, M. (Org.) Catástrofe e representação. São Paulo: Escuta, 2000. p.13-71.

FREUD, S. Recomendações aos médicos que exercem a psicanálise. 1912. In: FREUD, S. Obras Completas. Rio de Janeiro: Imago, 1976. p.149-62. v.12.

FREUD, S. Algumas reflexões sobre a psicologia escolar. 1914. In: FREUD, S. Obras Completas. Rio de Janeiro: Imago, 1974. p.281-88. v.12.

FREUD, S. Fixação em traumas: o inconsciente. 1917a. Conferências Introdutórias sobre psicanálise. In: FREUD, S. Obras Completas. Rio de Janeiro: Imago, 1976. p.323-36. v.16.

FREUD, S. Uma dificuldade no caminho da psicanálise. 1917b. In: FREUD, S. Obras Completas, v.XVII. Rio de Janeiro: Imago: 1976. p.171-82. v.17.

FREUD, S. Além do princípio do prazer. 1920. In: FREUD, S. Obras Completas. Rio de Janeiro: Imago, 1976. p.17-88. v.18.

FREUD, S. Prefácio à juventude desorientada de Aichhorn. 1925. In: FREUD, S. Obras Completas. Rio de Janeiro: Imago, 1976. p.341-6. v.19.

FREUD, S. O mal-estar na civilização. 1930. In: FREUD, S. Obras Completas. Rio de Janeiro: Imago, 1969. p.81-174. v.21.

FREUD, S. Novas conferências introdutórias sobre psicanálise: explicações, aplicações e orientações. 1933. In: FREUD, S. Obras Completas. Rio de Janeiro: Imago, 1976. p.167-92. v.22.

FREUD, S. Análise terminável e interminável. 1937. In: FREUD, S. Obras Completas. Rio de Janeiro: Imago, 1976. p.247-88. v.23.

FREUD, A. O tratamento psicanalítico das crianças. Rio de Janeiro: Imago, 1971.

HALL, S. A identidade cultural na pós-modernidade. Rio de Janeiro: DP\&A, 2003.

KUPFER, M. C. Educação para o futuro: psicanálise e educação. São Paulo: Escuta, 2001.

KUPFER, M. C. Freud e a educação: o mestre do impossível. São Paulo: Scipione, 1989. 
MACIEL, M. R.

LASCH, C. O mínimo eu. São Paulo: Brasiliense, 1987.

LASCH, C. Cultura do narcisismo. Rio de Janeiro: Imago, 1983.

LIPOVETSKY, G. A era do vazio. Lisboa: Relógio d'Água, 1993.

MILLOT, C. Freud anti-pedagogo. Rio de Janeiro: Zahar, 1987.

PATTO, M. H. A produção do fracasso escolar. São Paulo: T. A. Queiroz, 1990.

SENNETT, R. O declínio do homem público: as tiranias da intimidade. São Paulo: Companhia das Letras, 1998.

SENNETT, R. A corrosão do caráter. Rio de Janeiro: Record, 2000.

VALLE, L. Os enigmas da educação: paidéia democrática entre Platão e Castoriadis. Belo Horizonte: Autêntica, 2002.

WINNICOTT, D. A criatividade e suas origens. In: WINNICOTT, D. (Org.) O brincar e a realidade. Rio de Janeiro: Imago, 1975. p.95-120.

WINNICOTT, D. Comunicação e falta de comunicação levando ao estudo de certos opostos. In: WINNICOTT, D. (Org.) O ambiente e os processos de maturação. Porto Alegre: Artes Médicas, 1983. p.163-74.
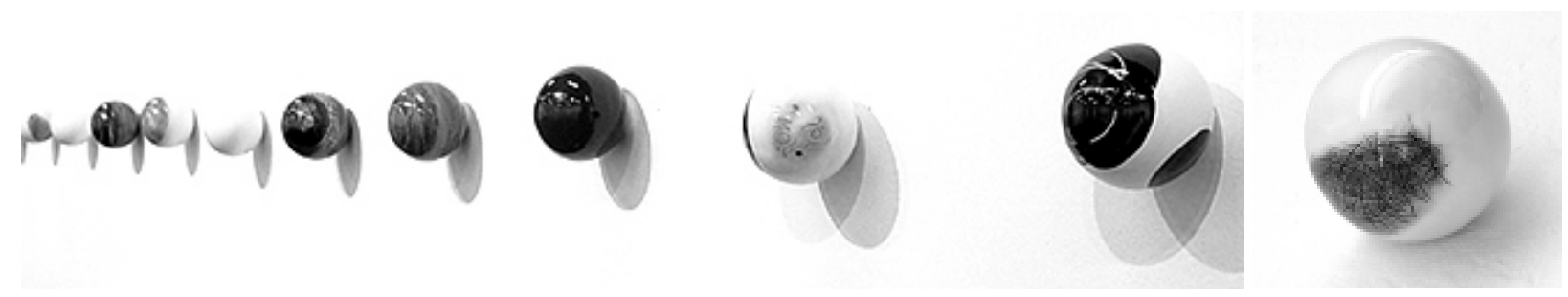

MACIEL, M. R. Sobre la relación entre educación y psicoanálisis dentro del ambiente de las nuevas formas de subjetivación. Interface - Comunic., Saúde, Educ., v.9, n.17, p.333-42, mar/ago 2005.

El presente artículo establece relaciones entre educación y psicoanálisis dentro del contexto de las nuevas formas de subjetivación. Discute las referencias de Freud sobre la educación, así como algunas de las publicaciones más recientes sobre el tema.

Considerando las transformaciones por las que estas dos áreas han pasado en sus teorías y en sus prácticas, propone una intersección entre ellas que tendría lugar en el espacio escolar, contribuyendo a la existencia de sujetos más creativos.

PALABRAS CLAVE: educación; psicoanálisis; singularidades; creatividad. 